\title{
O CFESS na defesa das condições de trabalho e do projeto ético-político profissional ${ }^{*}$
}

\author{
CFESS in defense of the working conditions and \\ the ethical-political professional project
}

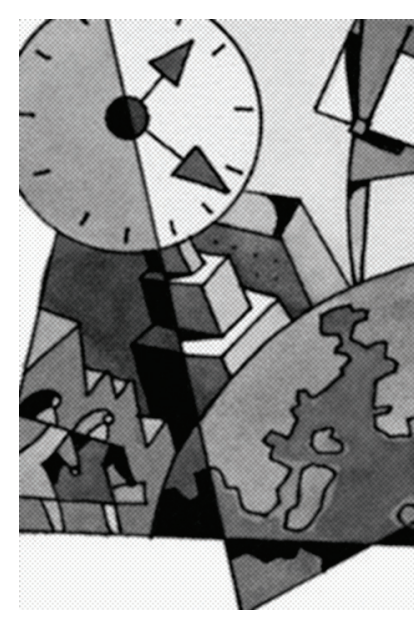

\section{Silvana Mara de Morais dos Santos*}

Resumo: Este texto analisa a ação política do CFESS na defesa das condições de trabalho do(a) assistente social e na materialização do projeto ético-político profissional neste tempo de crise estrutural do capital, momento histórico de extrema imposição da mercantilização sob todas as dimensões da vida social e de banalização da vida humana.

Palavras-chave: Condições de trabalho. Projeto profissional. Política.

Abstract: This paper analyzes CFESS's political action in defense of the social worker's working conditions and the materializing of the ethical-political professional project in this time of structural

* Este artigo agora revisado foi originalmente apresentado na forma de palestra: "Condições de trabalho e a materialização do projeto ético-político profissional" durante o XIII CBAS realizado em Brasília no período de 31 de julho a 5 de agosto de 2010. O XIII CBAS teve como tema geral "Lutas sociais e exercício profissional no contexto de crise do capital: mediações e consolidação do projeto ético-político profissional". A palestra foi realizada no dia 4/8/2010 em mesa dividida com a profa. dra. Marilda Iamamoto - Uerj. Foi um grande prazer e enorme responsabilidade dividir esta mesa com a profa. Marilda, que é, sem dúvida, uma grande referência intelectual da categoria profissional. Este artigo será também publicado pelo CFESS numa edição especial que reunirá as palestras proferidas no XIII CBAS.

* Doutora em Serviço Social, professora do Departamento de Serviço Social da UFRN — Natal/RN, Brasil; coordenadora do Grupo de Estudos e Pesquisa em Trabalho, Ética e Direitos (Gepted) e Coordenadora da Comissão de Ética e Direitos Humanos do CFESS — Gestão 2008-11. E-mail: sillmorais@gmail.com. 
crisis of the capital. This is a historical moment of extreme imposition of commodification in all dimensions of the social life and of trivializing of the human life.

Keywords: Working conditions. Professional project. Policy.

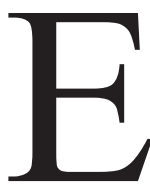

ste artigo tem o objetivo de socializar aspectos da agenda do conjunto CFESS-Cress e notadamente da ação política do CFESS que se direcionam para a defesa das condições de trabalho e materialização do projeto ético-político profissional, considerando os desafios contemporâneos presentes nas condições e relações de trabalho, no contexto de defesa dos interesses da classe trabalhadora e no universo de um projeto profissional que se articula na perspectiva da construção de um projeto societário anticapitalista.

Refletir sobre o tema proposto envolve um conjunto de determinações, dimensões e situações, postas por condições objetivas e subjetivas a que estamos submetidos e os diversificados espaços de realização do exercício profissional do(a) assistente social. Podemos afirmar que é um tema difícil e delicado. Difícil porque sua abordagem exige apreender um conjunto de determinações sócio-históricas e suas implicações na vida cotidiana. E delicado porque refletir sobre condições de trabalho tem profundas implicações nas condições de vida, de como os indivíduos se movimentam para o atendimento de suas necessidades e de como essas condições de trabalho promovem ou obstaculizam, no tempo presente, o desenvolvimento da individualidade e a formação do sujeito profissional, em sua expressão individual e coletiva.

As condições e relações de trabalho só podem ser analisadas em sua densidade histórica no contexto da sociabilidade capitalista em suas particularidades. Isto implica apreender o sistema do capital simultaneamente como modo de produção e processo civilizatório que promove e desenvolve formas objetivas e ideológicas subjacentes ao universo burguês, na perspectiva de construir um tipo de individualidade que corresponde à dinâmica societária naquilo que ela tem de avanço e no que tem de entrave ao pleno desenvolvimento humano. Este modo de produção, tendo surgido no âmbito da sociedade feudal, vivenciou uma fase de transição longa e contraditória que se inicia no século XIII e "apenas com a Revolução Industrial, que ocorreu, na segunda metade do século XVIII, o novo modo de produção capitalista se consolida e se impõe definitivamente" (Mandel, 
2001, p. 11). Como projeto civilizatório, implica reconhecer a vigência de uma nova racionalidade, referente ao horizonte ideológico burguês, que estrutura as relações sociais, atravessando, progressivamente, todas as dimensões da vida social e, assim, podemos pensar que o capitalismo

construiu não apenas os seus aparelhos materiais de produção mas, também, e, fundamentalmente, as suas premissas ideológico-políticas. Fez "terra arrasada" da maneira pela qual as sociedades anteriores, e cada um dos seus indivíduos, compreendiam a vida, a história, o mundo. Destruiu toda a institucionalidade anterior. (Dias, 1997, p. 27)

Para análise do tema proposto é fundamental partirmos de alguns pressupostos que embora fundamentais para o entendimento das questões que envolvem o tema, não teremos condições de desenvolvê-los neste espaço. Quando Marx define que o seu objeto de estudo é, em primeiro lugar, a produção material não se trata de contrapor sociabilidade à individualidade, nem economia à política e ao cotidiano, mas de estabelecer uma perspectiva de totalidade para a compreensão das formas, das determinações e dos aspectos da produção material da vida humana. Materialidade abrange as determinações econômicas, políticas e culturais, por onde se estruturam as formas ideológicas e o conteúdo "espiritual" de um tempo histórico. E neste processo de estruturação da sociabilidade reconhecemos o trabalho como momento fundante da vida humana que torna possível a constituição do ser social e a reprodução da vida cotidiana.

O sistema do capital constitui as relações sociais fundadas na exploração do trabalho e na reprodução permanente da desigualdade social. É sempre bom lembrar que a exploração do trabalho e as iniciativas para dificultar e mesmo obstaculizar o desenvolvimento do processo de consciência e de construção de um projeto político da classe trabalhadora integra a dinâmica e a lógica da sociedade capitalista e suas estratégias de hegemonia, não sendo, portanto, uma questão contemporânea ou determinada a partir da década de 1970 mediante a crise estrutural do capital. Exploração e desigualdade social também não são problemas/falhas/defeitos que possam ser ajustados por dentro da ordem burguesa, pois constituem modos de ser da sociabilidade sob o comando e direção do capital.

$\mathrm{Na}$ conjuntura atual, todo esse processo se agrava. Desemprego, inserção precária no universo do trabalho, múltiplas formas de violência na vida cotidiana, criminalização dos movimentos sociais, de suas lideranças, criminalização 
da pobreza; judicialização da questão social e instituição do "Estado penal" dão o tom do cenário contemporâneo por onde se movimentam os sujeitos profissionais nos diferentes espaços sócio-ocupacionais.

Tudo o que acontece na vida cotidiana, por um conjunto amplo de mediações, é determinado pelas condições estruturais da sociedade e pela ação dos sujeitos. E é exatamente por essa razão que o entendimento das condições de trabalho dos(as) assistentes sociais exige o pleno conhecimento das determinações e implicações da crise estrutural do sistema do capital (Mészáros, 2002) e das iniciativas de resistência da classe trabalhadora. Desde a década de 1970 que o capital desenvolve estratégias que visam o enfrentamento da sua própria crise e restauração da sua hegemonia sem ameaças quanto à constituição do poder político da classe trabalhadora. Utiliza variadas ações que, ao reestruturar a produção, define padrões de atuação do Estado frente à questão social, mas, também, impregna nas relações sociais, valores que orientam os indivíduos em sua conduta pessoal e profissional. Trata-se da formação e disseminação de um ethos, sempre atualizado conforme as necessidades do capital. É neste sentido que refletir sobre condições de trabalho implica apreender como se efetivam essas determinações do capital na vida social e particularmente na classe trabalhadora e no universo do Serviço Social.

As condições objetivas e subjetivas impostas pelo capital à classe trabalhadora e à vida social, longe de se constituir referências secundárias ou servir de cenário para a vida cotidiana, são, na verdade, determinações que tecem modos de ser e viver. No entanto, é fundamental lembrar que esse é um movimento contraditório, aberto à luta de classes, permeável à ação das forças organizadas do trabalho, à atuação e reflexão crítica dos sujeitos individuais e coletivos, que também fazem a história, ainda que em condições bastante adversas.

Esses são pressupostos sobre os quais nos apoiamos para pensar as condições de trabalho de assistentes sociais e as possibilidades de materialização do projeto ético-político profissional no capitalismo contemporâneo. E é nesse tempo sócio-histórico que entender as condições e relações de trabalho vivenciadas pela classe trabalhadora e em particular por assistentes sociais, na condição de trabalhador(a) assalariado(a), coloca exigências que passam pela apreensão de um conjunto de mediações para localizar a intensidade e as modalidades de mudanças impostas pelo capital e que incidem nas relações entre Estado-sociedade e notadamente no novo papel que o Estado assume nas res- 
postas às expressões da questão social; na forma de lidar com as necessidades, reivindicações e lutas do trabalho e nas exigências e demandas postas ao Serviço Social. Essas questões têm sido analisadas num movimento teórico denso, posto que numa perspectiva de totalidade, são objetos de estudo e reflexões na produção bibliográfica da profissão nos últimos trinta anos.

Todo esse processo de mudanças determinado por movimentos objetivos do capitalismo contemporâneo que incide no Serviço Social chega ao conjunto CFESS-Cress de diferentes e combinadas formas. A articulação dessas modalidades de apreensão do exercício profissional evidenciam o aprimoramento da comunicação e da relação política entre o conjunto CFESS-Cress e a categoria profissional. Tais mudanças advêm de profissionais que buscam essas entidades e socializam o universo de novas exigências e demandas postas no seu trabalho. São profissionais que nomeiam entraves e limites institucionais que revelam, simultaneamente, o modo de agir do Estado nas respostas às expressões da questão social, por meio de políticas sociais com ênfase na focalização e em situações específicas de vivência da pobreza e o modo como os indivíduos são tratados pelo sistema do capital, diante das respostas às suas necessidades e projetos de vida. Praticamente nas diferentes áreas de atuação profissional, as narrativas trazidas por assistentes sociais ao conjunto CFESS-Cress informam e, por vezes, problematizam o processo intenso de banalização da vida, expressos em múltiplas formas de violência e de violação dos direitos vivenciadas pelos indivíduos, usuários do Serviço Social.

Necessidades reais da vida cotidiana dos usuários são respondidas com estratégias que combinam intensificação na responsabilidade individual e familiar com políticas e programas sociais que asseguram, em condições raras de bom funcionamento, acesso ao mínimo, algo que seja capaz tão somente de tornar a vida física ainda possível. São inúmeras situações graves, com determinações econômica, política e cultural próprias das particularidades de um país de capitalismo periférico, com cultura política autoritária e processos de democratização inconclusos, que são respondidas com "políticas de incentivo". Incentivo à solidariedade individual e comunitária; incentivo à "mágica" do empreendedorismo, da economia solidária, do "emponderamento" e da autoestima. Na contramão do atendimento às necessidades humanas por meio de políticas sociais de caráter universal e reconhecedoras da diversidade, avançam e se consolidam políticas de privatização e mercantilização da educação, da seguridade social e do meio ambiente. Tudo isto sendo realizado com a presen- 
ça explícita do Estado, que assegura legitimidade política e caminhos institucionais à busca sem limites do capital para recompor e promover sua capacidade de expansão e dominação ideológicAs condições e relações de trabalho dos(as) assistentes sociais também chegam ao conjunto CFESS-Cress como resultado da efetivação da política nacional de fiscalização $(\mathrm{PNF})^{1}$ do conjunto que possibilita apreender perfil, demandas e respostas profissionais vistas em seus processos, possibilidades, dinâmicas, tensões e limites vividos no cotidiano. A PNF se estrutura na dimensão afirmativa de princípios e compromissos conquistados na trajetória do Serviço Social; na dimensão político-pedagógica e na dimensão normativo-disciplinadora. Estas três dimensões da PNF se encontram organicamente vinculadas e orientam os conselhos regionais em sua execução. Revelam, também, o processo de amadurecimento teórico-ético-político e normativo do conjunto CFESS-Cress que aprimorou os instrumentos para a fiscalização do exercício profissional, superando concepções e práticas de fiscalização fundadas em valores corporativos e voltadas para o desenvolvimento de ações de controle meramente burocrático e punitivo sobre os profissionais. Podemos afirmar que a PNF possibilita apreender as inúmeras dificuldades, contradições e os desafios postos à materialização do projeto ético-político profissional.

Outro momento de extrema relevância que favoreceu a socialização e as reflexões sobre as condições de trabalho dos assistentes sociais foram os seminários realizados de forma gratuita, com transmissão via internet, pelo CFESS-Cress. Entre 2009 e 2010 foram realizados quatro seminários que versaram sobre o trabalho profissional na Saúde, na Assistência Social, na Previdência e no campo sociojurídico. Foram momentos demasiadamente ricos de debate em que o exercício profissional esteve no centro da reflexão. Além disso, mesmo com particularidades oriundas da natureza de suas intervenções, os conselhos regionais, o CFESS, a Abepss e a Enesso se empenham teórica e politicamente para apreender o Serviço Social na história, com interlocuções com o que de melhor a área conseguiu produzir para entender a realidade contemporânea e a profissão na perspectiva do pensamento crítico.

1. A política nacional de fiscalização (PNF) do exercício profissional do assistente social foi aprovada no XXV Encontro Nacional CFESS-Cress em 1996, foi revisada a partir de contribuições dos Cress e do CFESS e aprovada em plenária nacional CFESS-Cress, de caráter deliberativo, realizada em Brasília (DF) em 2007. 
Considerando que são muitas e complexas as questões que objetivam o universo das condições e relações de trabalho, sintetizarei alguns aspectos que se manifestaram de forma recorrente em todas as áreas de atuação do(a) assistente social, obviamente com maior ou menor incidência e intensidade em uma ou outra área:

1. O Estado efetiva seu papel político para atender prioritariamente os interesses do capital em detrimento do atendimento às necessidades humanas, impondo alterações profundas no modo de ser das políticas sociais e das instituições que as realizam no que se refere aos objetivos e critérios de acesso institucionais que passam a operar cada vez menos na perspectiva dos direitos e mais na lógica do mercado com sua ânsia de eficácia e produtividade.

2. Verifica-se perda crescente de condições de infraestrutura para a realização do trabalho, que seguindo variações e particularidades nos diferentes espaços sócio-ocupacionais revelam falta de equipamentos de toda ordem, de material de informática; meios de transporte para realização de atividades que requerem deslocamento dos profissionais, falta de material de consumo e ênfase em espaços inadequados para o atendimento profissional, visto que possuem escassa iluminação, ventilação e segurança. Há indicações, também, referentes à falta de arquivos disponíveis para guarda de material técnico de caráter reservado, de uso e acesso restrito por assistentes sociais e ausência de espaço físico com possibilidades para reuniões e estudos, de caráter individual e em equipe.

3. A falta de condição de infraestrutura nos espaços institucionais faz com que não haja como garantir a privacidade dos usuários naquilo que for revelado durante a intervenção profissional e que o assistente social não tenha assegurado as condições para manter o sigilo profissional. Isto se agrava em situações em que usuários tiveram seus direitos violados e buscam o Serviço Social na perspectiva de recompor esses direitos. Por exemplo, quando crianças e adolescentes foram vítimas de abuso e/ou exploração sexual, a falta de condições de trabalho, notadamente a ausência de espaço com recursos para garantir o sigilo profissional, gera uma situação em que em vez de proteção institucional, usuários são submetidos à exposição, vivenciando outra violação de direito no momento do atendimento. 
Este aspecto tem profundas implicações éticas, pois a ausência de condições objetivas para assegurar o sigilo profissional leva o profissional a não cumprir o que consta no Código de Ética em seu artigo $2^{\circ}$, inciso $d$ que trata da "inviolabilidade do local de trabalho e respectivos arquivos e documentação, garantindo o sigilo profissional" e o que consta na Resolução CFESS n. 493/2006, ${ }^{2}$ que em seu artigo $3^{\circ}$ afirma que "o atendimento efetuado pelo assistente social deve ser feito com portas fechadas, de forma a garantir o sigilo". Esta resolução é uma estratégia do CFESS em defesa das condições de trabalho do(a) assistente social.

4. Temos que considerar também que em algumas instituições em que há sistemas sofisticados de informatização, os recursos existentes são destinados ao controle excessivo do trabalho e dos indivíduos, e não para facilitar dinâmicas e processos de atendimento às reais necessidades dos usuários. A tecnologia se destina mais para disciplinar, unificar e burocratizar procedimentos, por meio de uma super racionalidade burocrática.

Em todas as áreas de inserção profissional prevalece esse processo de deterioração das condições de trabalho, que só podem ser analisadas em suas particularidades na medida em que são realizados estudos e pesquisas sobre o trabalho profissional. Como ilustração dessa difícil realidade, destaco pesquisa recente ${ }^{3}$ sobre as condições de trabalho de assistentes sociais inseridos nos Cras em municípios do estado do Rio Grande do Norte. Tal pesquisa apresenta vários dados, que ao mesmo tempo em que mostram a expansão do trabalho de assistentes sociais, notadamente no âmbito da política de assistência social, adensa reflexões que possibilitam apreender de modo mais concreto que isto acontece sob condições de inserção precária. Alguns dados desta pesquisa para ilustrar este processo: foram entrevistadas 89 assistentes sociais. Desse universo, $69,66 \%$ estão inseridas nos Cras entre menos de um a cinco anos. Quanto à forma de acesso no Cras: $54,55 \%$ receberam convite; $25 \%$ por processo seletivo e $20,45 \%$

2. Resolução CFESS n. 493/2006 “dispõe sobre as condições éticas e técnicas do exercício profissional do assistente social".

3. Pesquisa realizada na tese de doutorado de Mara Jales intitulada $A$ interiorização e a expansão dos espaços sócio-ocupacionais do Serviço Social no RN (2004-2008): um estudo das competências profissionais, do Programa de Pós-graduação da UFPE, sob a orientação, da profa. Ana Elizabete Mota. 
por indicação, evidenciando, desse modo, o quanto a luta/campanha pela realização de concurso público, lançado pelo conjunto CFESS-Cress, é fundamental. Os dados sobre a origem das indicações ou convites para atuar nos Cras revelam as complexas e históricas relações da formação sócio-histórica do país e da Região Nordeste, no que se refere à instituição e reprodução de uma cultura política da tutela, do autoritarismo e de privatização do espaço público. Para 53,57\% a indicação foi realizada pelo prefeito; 35,71\%, pela Secretaria de Assistência Social; 7,14\%, pelo afiliado político partidário, e 3,57\% por vereador. Do total $32,53 \%$ têm dois vínculos de trabalho e $82,14 \%$ possuem mais de um vínculo de trabalho. Lembra a autora que é necessário considerar como agravante das condições e relações de trabalho a reprodução da cultura política autoritária que prevalece nos municípios.

Acrescente-se a todos os aspectos já assinalados as implicações que essas condições e relações de trabalho têm na subjetividade dos indivíduos. Sobre a dimensão subjetiva, poderíamos refletir várias questões, mas elejo apenas uma que me parece comum a todas as áreas de atuação. Trata-se dos processos de adoecimento dos trabalhadores e trabalhadoras, em particular dos(as) assistentes sociais, que são gerados a partir da inserção no trabalho em tempo de mundialização do capital. Problemas variados de coluna, gastrites, úlceras, depressões e síndromes as mais diversas são reveladoras de indivíduos vivendo em situações agudas de competitividade, burocratismo e violação de direitos. Ainda são invadidos por demandas do trabalho a todo instante por meio eletrônico, que permite que com um simples acesso ao e-mail o indivíduo comece a responder às demandas de trabalho.

São processos de adoecimentos que nos colocam diante de situações de medo, pânico, desesperança quanto à possibilidade do futuro. Profissionais que são contratados por projetos com validade de um ano falam que conseguem levar uma vida "normal" durante os seis primeiros meses porém, nos seis meses seguintes têm a nítida sensação que vivem um tempo ausente, pois não conseguem viver o presente, angustiados que estão com a proximidade do desemprego e nem conseguem se lançar na busca por novas possibilidades profissionais. Viver no tempo presente de forma ausente é talvez a forma mais intensa de retirar de mulheres e homens a capacidade e a possibilidade de elaborar o futuro em novas bases.

Em síntese, podemos afirmar que assistentes sociais vivenciam em todos os espaços sócio-ocupacionais as tendências de precarização e exploração do 
trabalho. Com isto não temos dúvidas em afirmar que as tendências mais gerais do mercado de trabalho - flexibilização/desregulamentação/desterritorialização - , que tanto produzem instabilidade e insegurança, comparecem nas condições de trabalho de assistentes sociais com um agravante, pois eles lidam com indivíduos diretamente inseridos em situações de violação de direitos, de violência e de desigualdade social em toda a sua intensidade.

Diante disso, passo a ressaltar as ações estratégicas desenvolvidas no âmbito do conjunto CFESS-Cress que se voltam para o enfrentamento dessa situação e que se destinam a fortalecer o processo de materialização do projeto ético-político profissional. Porém não se trata aqui de fazer uma narrativa de atividades e ações desenvolvidas, mas de ressaltar processos de resistência e de luta construídos coletivamente. E neste sentido é fundamental o entendimento de que não nascemos assistentes sociais. Nos tornamos assistentes sociais, e este movimento de tornar-se é histórico, é diverso na história de cada um/uma de nós. Temos que considerar aqui a necessária temporalidade para gestar seja o profissional assistente social em sua dimensão individual, seja o coletivo da categoria profissional. Do ponto de vista da formação individual do profissional, o processo tem início no curso de graduação em Serviço Social, mas esse tempo se amplia por meio da participação política dos estudantes e posteriormente nas inserções em nível de pós-graduação, nas experiências profissionais cotidianas e inserção em espaços de representação e organização política. Não podemos esquecer que a maioria dos(as) assistentes sociais, ao entrar na universidade, possuía projetos voltados para as necessidades do "eu", com aspirações e buscas ensimesmadas na própria singularidade.

Do ponto de vista da construção coletiva do projeto ético-político, temos uma cultura profissional construída nesses mais de trinta anos que nos separa do III CBAS, denominado "Congresso da Virada", realizado em 1979, em São Paulo, construção que repõe e recria o sentido de projeto coletivo. Se as dificuldades e mesmo derrotas existem, as conquistas são muitas e valiosas, e tudo isto tem o sabor todo especial porque são derrotas e conquistas, entendidas numa relação dialética que favorece, potencializa e oxigena nosso movimento de apreender e atuar profissional e politicamente nas contradições e de seguir adiante qualitativamente melhor.

Diferentes gerações se dedicaram à construção desse projeto profissional. No cotidiano e nos momentos coletivos (seminários/congressos/encontros descentralizados e nacional do conjunto CFESS-Cress), espaços esses instituídos 
democraticamente no Serviço Social, se efetiva o encontro de estudantes e assistentes sociais que realizam belas e verdadeiras sínteses entre as diferentes gerações do Serviço Social brasileiro. $\mathrm{O}$ ato público ${ }^{4}$ constituiu-se numa importante manifestação política que contou com a presença de estudantes e profissionais de diferentes gerações e estados do Brasil, além de representantes de movimentos sociais e de partidos políticos de esquerda que apoiaram esta luta. $\mathrm{O}$ ato público foi realizado em defesa do PLC n. 152/2008 que define a jornada máxima de trabalho de assistentes sociais em 30 horas semanais sem redução salarial, aprovado no plenário do Senado Federal, em Brasília (DF) no dia 3 de agosto e sancionado pelo Presidente Luis Inácio Lula da Silva no dia 26 de agosto de 2010. A diminuição da jornada de trabalho sem redução salarial constitui-se reivindicação e luta histórica da classe trabalhadora por melhores condições de trabalho.

O CFESS desde 2008 interfere politicamente neste processo por meio de reunião com autor e relatores do projeto na câmara; reunião entre o autor do projeto e representantes do conjunto CFESS-Cress; participação em audiências públicas e debates; elaboração de notas técnicas com o objetivo de explicar as razões que nos possibilitam afirmar que a categoria de assistentes sociais pela natureza do trabalho desenvolvido insere-se entre as categorias profissionais que estão submetidas a situações de adoecimento, com níveis acentuados de stress, desgaste físico e emocional. Isto porque convivem diariamente com demandas profissionais que explicitam o quadro de violência e de violação de direitos a que estão submetidos os indivíduos, usuários do Serviço Social, que vivenciam as consequências da desigualdade social e de múltiplas formas de opressão em toda sua intensidade e manifestação na vida cotidiana. Esta conquista, portanto, tece possibilidades para que assistentes sociais possam trabalhar em condições mais favoráveis para se refazerem subjetivamente dos im-

4. No dia 3 de agosto de 2010 durante, o XIII CBAS, foi realizado em Brasília (DF) ato público em defesa do Projeto de Lei n. 152/2008, de autoria do deputado Mauro Nazif (PSB-RO). Coordenado pela comissão organizadora do XIII CBAS (CFESS/Abepss/Cress-DF), o ato reuniu aproximadamente 3 mil pessoas, entre assistentes sociais e representantes de movimentos sociais e partidos políticos de esquerda. Depois do ato público, as professoras Ivanete Boschetti (presidente do CFESS), assistente social Marinete Cordeiro (CFESS), Elaine Behring (presidente da Abepss), assistente social Fernanda Fernandes (presidente do Cress-DF) e Mario Pereira (estudante, representante da Enesso) tiveram audiência com o presidente do Senado. A manifestação continuou nas galerias do Congresso Nacional até a noite, quando finalmente o PLC entrou em votação e foi aprovado por unanimidade. 
pactos próprios de um tipo de trabalho que evidencia situações em que os usuários, além de estarem historicamente interditados do acesso ao circuito dos direitos, estão subjetivamente despotencializados para viver.

Nesse tempo histórico de construção e materialização do projeto ético-político profissional, a realidade em sua dinamicidade e dimensão contraditória torna-se o chão histórico prenhe de lições cotidianas por meio do protagonismo das lutas da classe trabalhadora e dos sujeitos profissionais que passaram a apreender as necessidades reais vivenciadas pela população como demandas postas ao Serviço Social. Direito ao trabalho, à autonomia de organização sindical por ramo de atividade e não por categoria profissional; acesso à seguridade social pública e universal; acesso aos direitos sociais, políticos e civis e aqueles relacionados à diversidade humana - como liberdade de orientação e expressão sexual, direito à igualdade e à identidade de gênero ${ }^{5}$, direito à diversidade étnico-racial - emergiram como demandas concretas no cotidiano profissional e por isso adentraram na agenda de lutas do conjunto CFESS-Cress.

Nas últimas três gestões do CFESS tivemos a realização de campanhas nacionais que se direcionam para a defesa da diversidade humana e dos direitos humanos. ${ }^{6}$ A "Campanha de combate ao racismo: o Serviço Social mudando o rumo da história" desenvolvida pela gestão CFESS-Cress (2002-05); a campanha "Assistente social na luta contra o preconceito: pela liberdade de orientação e expressão sexual" efetivada pela gestão CFESS-Cress (2005-08) ${ }^{7}$ e a campanha dessa gestão CFESS-Cress (2008-11), "Trabalho, direitos humanos e riqueza no Brasil”, que por meio de diferentes abordagens de comunicação tratou o tema em

5. Integram as deliberações do $38^{\circ}$ Encontro Nacional CFESS-Cress, no eixo Ética e Direitos Humanos, uma proposição que visa "aproximar a categoria profissional do debate contemporâneo acerca do uso do nome social nos espaços públicos e privado e no acesso às políticas públicas para a população LGBT, considerando o respeito à diversidade de orientação sexual e a identidade de gênero". Neste momento sob a responsabilidade do CFESS, por meio de sua assessoria jurídica, está em processo de elaboração procedimentos para assegurar ao(a) assistente social que solicitar o nome social na carteira de identidade profissional de modo a garantir o direito à identidade de gênero.

6. No último encontro nacional CFESS-Cress de cada gestão, é escolhido um tema que será trabalhado durante toda a gestão seguinte na forma de campanha, que envolve o desenvolvimento de múltiplas maneiras de comunicação (cartaz/spot de rádio/banner/folder etc.) e promoção de diversos debates.

7. Como parte integrante dessa campanha o CFESS instituiu a Resolução n. 489/2006, que "estabelece normas vedando condutas discriminatórias ou preconceituosas, por orientação e expressão sexual por pessoas do mesmo sexo, no exercício profissional do assistente social, regulamentando princípio inscrito no Código de Ética Profissional”. 
suas determinações concretas. No universo dessas campanhas, a violação dos direitos humanos foi analisada em relação com a desigualdade social e com a exploração do trabalho, rompendo com a visão abstrata e liberal dos direitos humanos.

As campanhas assinaladas interferem nas condições de trabalho ao possibilitarem a categoria refletir sobre temas polêmicos, em geral permeados no cotidiano por concepções que reiteram discriminação e preconceitos. Essas questões, ao serem trabalhadas no universo profissional contribuem para desmistificar e evidenciar situações consolidadas de opressão que levam os indivíduos, muitos dos quais usuários do Serviço Social, a viver sob o signo da violência e da violação de direitos.

As temáticas foram tratadas sob uma perspectiva de totalidade. Isto significa o entendimento da diversidade humana como parte constituinte da individualidade que só pode ser entendida em relação com a sociabilidade. A direção teórica dada possibilitou a crítica às teorias pós-modernas e seu aprisionamento na valorização e respeito à diferença entre os indivíduos em detrimento da defesa de um projeto societário de igualdade e liberdade substantivas que reconhece e valoriza a diversidade humana. Nas teorias pós-modernas prevalece o compromisso e o entendimento dos interesses de grupos e segmentos em detrimento do reconhecimento quanto à necessidade histórica objetiva e subjetiva de construir e fortalecer um projeto político da classe trabalhadora. A dimensão de classe tende a ser desconsiderada na apreensão da vida social.

As campanhas possibilitaram abordagens que superaram visões pós-modernas, economicistas e a afirmação de que a classe, em sua densidade histórica, é constituída de indivíduos que vivenciam determinadas condições objetivas, caracterizadas pelo não acesso à riqueza socialmente produzida e que subjetivamente são diversos, dentre muitas outras questões, quanto à identidade de gênero e étnico-racial, quanto à orientação sexual e o gênero. A classe é vida real que entra em movimento coletivo, que forja na luta a formação da consciência de classe e possibilidades de construção de um projeto coletivo emancipatório.

A cada dia estamos aprimorando nosso entendimento no âmbito do conjunto CFESS-Cress de que as condições de vida e de trabalho se alteram mediante processos de resistência e de luta. E que essas não são palavras mágicas. Resistência e luta são processos construídos, pensados e redefinidos em cada conjuntura e que não podem prescindir da presença de mulheres e homens que nomeiam, pela fala pública, situações concretas que sintetizam formas de opressão e de exploração. Constroem argumentos e decidem estratégias de luta. 
Resistência e luta são desafios permanentes quando pensadas numa perspectiva teórico-política que não cede às ilusões do economicismo, do politicismo, do eticismo, nem do pensamento conservador e moralista que insistem em renovar, com interferências, muitas vezes, por dentro de um projeto que tem compromisso com a emancipação humana.

Contra o pragmatismo, o conservadorismo e a suposta neutralidade defendidos pelo Serviço Social tradicional, o projeto profissional do Serviço Social brasileiro elaborado nos últimos trinta anos foi fundado na luta política por democracia, liberdade, trabalho e direitos. É na trincheira da resistência e do enfrentamento à desigualdade social que as entidades nacionais da categoria e assistentes sociais em diferentes recantos deste país assumiram explicitamente seu compromisso com os interesses do trabalho. O aprimoramento intelectual é entendido como condição para apreender o real em sua concretude e complexidade. Neste processo, a interlocução com a tradição marxista e posteriormente com o pensamento marxiano forneceu o alicerce teórico-metodológico para apreender a realidade sob uma perspectiva de totalidade. Três décadas depois podemos afirmar que a perspectiva da totalidade constituiu-se na grande conquista desse projeto profissional e, simultaneamente, no grande desafio da profissão na contemporaneidade. O projeto ético-político profissional é produto da ação dos sujeitos profissionais sob determinadas condições objetivas. Em cada momento histórico surgem novas exigências e desafios.

Nos anos de 1990, a categoria de assistentes sociais foi chamada a aprimorar o entendimento da ética e, desse modo, aperfeiçoar os instrumentos normativos no âmbito do Serviço Social. O atual Código de Ética profissional, aprovado em 1993, foi resultado de um amadurecimento das reflexões iniciadas na elaboração do Código de 1986, fruto de uma construção coletiva da categoria, mas que em face da realidade revelou-se insuficiente, entre outras questões, na subordinação imediata e sem mediações entre ética e política e na ausência de mediações entre projeto societário e projeto profissional.

É também de 1993 a renovação da Lei de Regulamentação da Profissão que, ao definir atribuições e competências profissionais, contribuiu para inscrever a profissão de Serviço Social num patamar qualificado no tratamento das expressões da questão social. Desse período em diante, aprofunda-se mais ainda o arsenal teórico-metodológico, ético-político e os instrumentos normativos. Merece destaque a capacidade que tem tido o conjunto CFESS-Cress de apreender questões e demandas postas no exercício profissional e discernir 
sobre a necessidade de objetivar a lei de regulamentação da profissão e o Código de Ética, por meio de resoluções apresentadas pelo CFESS no uso de suas atribuições legais e regimentais, que lhe são conferidas pela Lei n. 8.662/93. Do universo de inúmeras resoluções, destacaremos as mais recentes e que causaram debates polêmicos, colocando em primazia o exercício profissional e os desafios à materialização do projeto ético-político.

A Resolução CFESS n. 533/2008, que "regulamenta a supervisão direta de estágio no Serviço Social", parte do entendimento expresso na lei de regulamentação da profissão de que o exercício de tal atividade profissional é privativa de assistentes sociais. Considera os inúmeros debates sobre a relação entre o estágio e a PNF sistematizados pelos conselhos regionais na perspectiva de enfrentar os entraves, apreender desafios e qualificar a formação e o exercício profissional.

A Resolução CFESS n. 554/2009, que "dispõe sobre o não reconhecimento da inquirição das vítimas crianças e adolescentes no processo judicial, sob a metodologia do Depoimento Sem Dano/DSD, como sendo atribuição ou competência do profissional assistente social" é síntese de amplo debate no universo do Serviço Social brasileiro. Ao reconhecer a metodologia DSD como função própria da magistratura, possibilitou o debate sobre as atribuições e competências do(a) assistente social e as particularidades da profissão na sua inserção e defesa do sistema de garantia dos direitos das crianças e dos adolescentes. Compete ao(à) assistente social atuar nas complexas expressões da questão social na perspectiva de contribuir para a recomposição dos direitos violados. A participação em metodologias como o DSD e estratégias similares, centra o objetivo da intervenção na produção de provas para punir o sujeito agressor e, neste sentido, destoa dos objetivos do Serviço Social, além de obstaculizar a autonomia profissional no que se refere à definição dos procedimentos de abordagem do usuário em cada situação particular e das questões que merecem atenção e intervenção direta do profissional junto a crianças e adolescentes.

A Resolução CFESS n. 556/2009, que trata dos "procedimentos para efeito da lacração do material técnico e material técnico-sigiloso do Serviço Social", põe em discussão a relevância no arquivamento de material próprio do Serviço Social e da atenção que deve ter o profissional quando entra e quando conclui seu trabalho em determinada instituição frente às informações de caráter técnico e/ou sigiloso. De acordo com a resolução, 
o material técnico sigiloso caracteriza-se por conter informações sigilosas, cuja divulgação comprometa a imagem, a dignidade, a segurança, a proteção de interesses econômicos, sociais, de saúde, de trabalho, de intimidade e outros, das pessoas envolvidas, cujas informações respectivas estejam contidas em relatórios de atendimentos, entrevistas, estudos sociais e pareceres que possam, também, colocar os usuários em situação de risco ou provocar outros danos. ${ }^{8}$

Esta resolução articula-se à Resolução n. 493/2006 e com o próprio Código de Ética na atenção dispensada à questão do sigilo profissional e, desse modo, contribui com a melhoria das condições de trabalho ao fornecer os procedimentos e indicações que os profissionais devem seguir em situações específicas.

A Resolução CFESS n. 557/2009, que "dispõe sobre a emissão de pareceres, laudo, opiniões técnicas conjuntos entre o assistente social e outros profissionais", reconhece que o(a) assistente social pode atuar em equipe multiprofissional e desenvolver atividades junto com outros profissionais e visa assegurar particularidades do Serviço Social no desenvolvimento e na elaboração de trabalhos técnicos. Afirma que é "inadmissível, juridicamente, que em uma mesma manifestação técnica, tenha consignado o entendimento conjunto de duas áreas profissionais regulamentadas, sem que se delimite o objeto de cada uma, tendo em vista, inclusive, as atribuições privativas de cada profissão". Não há, nessa resolução, nenhum impedimento à realização de trabalho conjunto com outras áreas profissionais, no entanto delimita a necessidade de o assistente social atuar por meio de opinião técnica somente em matéria de sua área de atuação e de acordo com suas competências e atribuições privativas, conforme prevê a Lei n. 8.662/93. Esta resolução incide sobre as condições de trabalho porque assegura ao(a) assistente social que este deve emitir opinião técnica somente em matéria da sua área de atuação, ao tempo em que veda que outros profissionais possam subscrever entendimento técnico em matéria do Serviço Social. Garante, assim que o usuário tenha acesso as opiniões técnicas diversas sobre sua situação e favorece a autonomia de cada área profissional mesmo que o trabalho tenha sido realizado em equipe.

A Resolução CFESS n. 569/2010 "dispõe sobre a vedação da realização de terapias associadas ao título e/ou ao exercício profissional do assistente social" por entender que o desenvolvimento de terapias exige arsenal teórico-metodo-

8. Parágrafo único da referida resolução. 
lógico e uma série de procedimentos que não integram o processo de formação básica em Serviço Social. Diferentes profissões atuam em contato com indivíduos em suas condições objetivas e subjetivas, mas cada área tem suas competências e atribuições e se movimentam de acordo com a cultura profissional e com seus instrumentos normativos. A resolução não avalia a direção social das terapias. Adverte, porém, que seu uso exige conhecimento teórico-metodológico e habilidades específicas, pois estes trazem consequências práticas na vida dos usuários. $\mathrm{O}$ (a) assistente social tem plena liberdade para atuar com indivíduos, grupos, famílias e/ou comunidade e definir formas de acesso e atividades voltadas para o enfrentamento das expressões da questão social e da luta pela garantia dos direitos em conformidade com suas atribuições e competências profissionais.

Todas essas resoluções contribuem para a melhoria das condições de trabalho, pois regulamentam temas presentes no cotidiano profissional, na perspectiva de garantia das competências e atribuições profissionais e das condições éticas e técnicas para o exercício profissional do(a) assistente social. São questões que demandam reflexão e posicionamento profissional. As resoluções formam um importante arsenal jurídico-normativo que longe de engessar o trabalho profissional, alicerçam a qualidade e competência teórico-metodológica-ético-política e técnico-operativa nos limites da intervenção profissional, considerando suas competências, habilidades e atribuições privativas. São instrumentos de defesa e valorização do Serviço Social, dos serviços prestados à população usuária e à sociedade brasileira.

Nos diversos espaços de representação em que se insere o CFESS, sua atuação é marcada pela defesa dos interesses do trabalho. Em síntese, três grandes eixos articulam a luta política do conjunto CFESS-Cress e se objetivam em várias estratégias: 1) em defesa da qualidade na formação e no exercício profissional; 2) pelo direito à cidade para todas as pessoas sem racismo, sem desigualdade de gênero e sem homofobia/lesbofobia e transfobia; e 3) em defesa dos direitos humanos e da universalização das políticas sociais. Entre as estratégias destacamos: o plano de lutas em defesa do trabalho e da formação profissional, desenvolvido em parceria com a Abepss e a Enesso; a publicação de parâmetros de atuação do(a) assistente social nas políticas de assistência social e saúde e em processo de debate atualmente a possibilidade de elaboração dos parâmetros na área da Previdência Social e no campo sociojurídico. Destacam-se, ainda, o acompanhamento permanente de projetos de lei de interesse do Servi- 
ço Social e que se voltem à defesa dos direitos humanos; campanha pela realização de concurso público para assistentes sociais em diferentes espaços sócio-ocupacionais e a promoção de seminários nacionais para analisar questões e desafios referentes ao trabalho profissional. Duas estratégias de luta merecem atenção especial pela força mobilizadora que possuem e por situar politicamente a luta numa perspectiva crítica ao sistema do capital. Trata-se da luta pelo direito ao trabalho e à seguridade social pública e pelo direito à terra e à moradia com condições dignas e por ações estratégicas que favoreçam à plena implementação da política nacional de reforma urbana e reforma agrária.

A profissão ganha visibilidade no cenário nacional na defesa intransigente dos direitos humanos, sobressaindo-se lutas pela implementação do sistema de garantia dos direitos das crianças, adolescentes, jovens e pessoas idosas; ações em defesa dos direitos das pessoas com deficiência e/ou portadoras de transtorno mental; direitos sexuais e reprodutivos da mulher, pela constitucionalidade e plena implementação da Lei Maria da Penha e defesa dos direitos LGBT com aprovação do PLC n. 122/2006, que criminaliza a homofobia. São lutas que exigem conhecimento dos temas e suas polêmicas em profundidade e participação política com concepção fundada na defesa das políticas sociais universais e de um conjunto de marcos legais que se tornaram fundamentais para a realização dos direitos.

É nesse processo de luta pela efetivação de direitos que importantes mediações se objetivam, favorecendo o entendimento das complexas relações entre projeto profissional e projeto societário. Em todas as trincheiras de luta se explicitam as condições objetivas e subjetivas de um tempo histórico de crise do capital, marcado por um "continuum depressivo", posto que o capital não tem limites à sua expansão. Tudo ordena e desordena, acolhe e descarta, constrói e destrói. Inadvertidamente alguém pode supor que numa conjuntura de crise estrutural como esta o projeto ético-político profissional perde relevância e possibilidades concretas de materialização. Considerando que assistentes sociais atuam nas expressões da questão social e na mediação de direitos para atendimento às necessidades da população usuária, quanto mais esta categoria for capaz de decifrar e apreender as determinações sócio-históricas, mais terá condições para elaborar respostas profissionais qualificadas. A efetivação do projeto passa também pela capacidade dos profissionais para identificar a insuficiência das respostas do Estado e assim explicitar o que falta e o que restringe nas políticas e programas sociais tal como se apresentam. 
Como dissemos por ocasião da comemoração dos trinta anos do Congresso da Virada em CFESS Manifesta9 escrito na ocasião, "este projeto profissional não é uma carta de intenções. É um processo de construção permanente e cotidiana em defesa de uma perspectiva ética, teórica e política que subsidia assistentes sociais e as entidades nacionais da categoria para atuar em condições concretas. As respostas às demandas e aos desafios se objetivam no cotidiano. Não espalhamos ilusões. O projeto ético-político profissional requer um conjunto de mediações que articulem a luta por um projeto societário anticapitalista às estratégias de enfrentamento no tempo presente". A materialização do projeto profissional é simultaneamente conquista e desafio. No cotidiano é fundamental resgatar e manter viva a memória das lutas históricas desenvolvidas pela categoria em defesa dos direitos e das condições de trabalho e, neste sentido, o ato público de 3 de agosto de 2010 deve integrar essa memória de resistência e de luta como um dia inesquecível de mobilização e participação da categoria profissional.

Este é um projeto coletivo de uma categoria profissional que construiu e preserva por mais de três décadas procedimentos e instâncias de decisão democrática. A ação do CFESS é radicalmente contrária às formas de fazer política fundadas na judicialização das lutas sociais, no desrespeito aos instrumentos normativos do Serviço Social, na criminalização dos movimentos sociais e de suas lideranças. Buscamos a dimensão jurídica, sempre de modo contraditório para a defesa dos direitos. Nesses trinta anos, o projeto ético-político profissional superou inúmeros limites teórico-políticos e com razão militante não temeu forças opositoras conservadoras nem o debate democrático sobre grandes questões que permeiam a vida social e o cotidiano da profissão.

É um projeto, portanto, que se alimenta da realidade e busca fortalecer em cada situação concreta as possibilidades que emergem do solo profundo das contradições. Não é fácil apreender e atuar nas contradições. Exige a reflexão crítica permanente e a elaboração de estratégias cotidianas. Por isso, mais do que nunca precisamos estar atentos e fortes para não sucumbir à "confusão do espírito", ao conformismo, ao "pensamento único" e às falsas polêmicas. Precisamos de coragem, porque, como sinaliza Guimarães Rosa: "O correr da vida

9. O CFESS Manifesta é uma publicação permanente que traz o posicionamento ético-político do CFESS sobre questões, acontecimentos da vida social e sobre assuntos de interesse do Serviço Social. No site do CFESS $<$ www.cfess.org.br $>$ encontram-se publicados todos esses documentos. 
embrulha tudo, a vida é assim: esquenta e esfria, aperta e daí afrouxa, sossega e depois desinquieta. O que ela quer da gente é coragem". O projeto ético-político profissional se constrói numa processualidade histórica, com sujeitos profissionais que misturam diferentes trajetórias, histórias e experiências profissionais e políticas. Tem tido a força teórico-política e a direção ética para não sucumbir diante de um mundo em situação de barbárie e busca sua renovação incessantemente com posicionamento firme e estratégias criativas.

São mais de trinta anos na defesa dos direitos, na luta contra a exploração do trabalho e pela vigência de outro tipo de sociabilidade fundada na igualdade e liberdade substantivas. São trinta anos na luta pelo fortalecimento de um projeto político das classes trabalhadoras. Não podemos deixar que o projeto dominante desrealize a experiência histórica das classes trabalhadoras em suas lutas e em seus momentos de dor e de resignação.

Temos que ter a memória desse tempo de anticivilização e de violação de direitos não para nos paralisar perante os obstáculos e limites cotidianos, mas para que possamos com uma memória ativa construir com outros interlocutores, sujeitos individuais e coletivos, a transformação do presente. Construir um novo tempo histórico em que os indivíduos vivam sem exploração e sem opressão nada tem de ilusório. É possibilidade inscrita na vida real mediante a decadência objetiva e ideológica do capital no atendimento às necessidades humanas. Os compromissos éticos e políticos e o conjunto de lutas e ações em defesa dos direitos assumidos pelo Serviço Social brasileiro nesses mais de trinta anos alicerçam nossa participação efetiva na elaboração do futuro.

Artigo recebido em ago./2010 - Aprovado em set./2010

\section{Referências bibliográficas}

DIAS, Edmundo Fernandes. Textos didáticos: a liberdade (im)possível na ordem do capital — reestruturação produtiva e passivização. Campinas: IFCH/Unicamp, 1997.

MANDEL, Ernest. O lugar do marxismo na história. São Paulo: Xamã, 2001.

MÉSZÁROS, István. Para além do capital. Trad. Paulo Sérgio Castanheira e Sérgio Lessa. São Paulo/Campinas: Boitempo Editorial/Ed. Unicamp, 2002. 